\section{Losing the World After the Moose Have Gone Away}

\section{Christian Sorace}

Sometimes the plans to improve people's lives end up destroying them. When the Chinese government moved the nomadic Evenki people from the forests into urban settlements and confiscated their hunting rifles, they took away their livelihood. Gu Tao's film The Last Moose of Aoluguya documents how people survive, or slowly destroy themselves, after the catastrophe of losing their world.

Man is the being through whom nothingness comes to the world Jean-Paul Sartre

Gu Tao's documentary The Last Moose of Aoluguya (an da han) (2013) follows the life of Weijia, an Evenki hunter, artist, and alcoholic who $\mathrm{Gu}$ Tao described as 'the most lonely person in the forest' (Cunliffe 2015). Traditionally, the Evenki, also known as Tungus in Russia, are a culture of nomadic hunters that span the trans-Baikal region, Siberian taiga, Mongolia, and the forests of northern China. Although mainly concentrated in Russia, in the People's Republic of China there were 30,875 Evenkis as of the 2010 population census. In the forests of China's Great Xing'an ling Mountains (daxing anling), the lives of the Evenki have revolved around moose hunting and reindeer herding.

In 2003, the Chinese government relocated the Evenki from the forest into new settlements in nearby townships as part of a broader campaign of 'ecological migration' (shengtai yimin). The relocation policy hoped to accomplish the interrelated goals of protecting nature, while providing indigenous people with new apartments and urban amenities, folded into a larger plan of accelerating regional economic development. As part of the urbanisation process, the government confiscated the Evenkis' hunting rifles and banned hunting. For this reason, Weijia asserts that the Evenki hunter lifestyle is guilty before the law that confiscated their guns and evicted them from their land: 'I heard about four young hunters who got arrested for hunting. That was the end of our culture. They put us on trial. Guilty! Just drink myself to death. We'll just have to get used to it.' Weijia's life occupies the ambivalent no man's land between dying and adaption.

Not only are the Evenkis prohibited from hunting, there are no longer any moose to hunt. The local moose population has either been killed by illegal poachers (Weijia insinuates that the poachers are mainly Han Chinese) or migrated elsewhere due to de-forestation. In the movie, Weijia and his friend Mao Xia search the forest in vain for signs of moose. All they find are sun bleached moose bones and rusted poacher traps, but no trace of living presence.

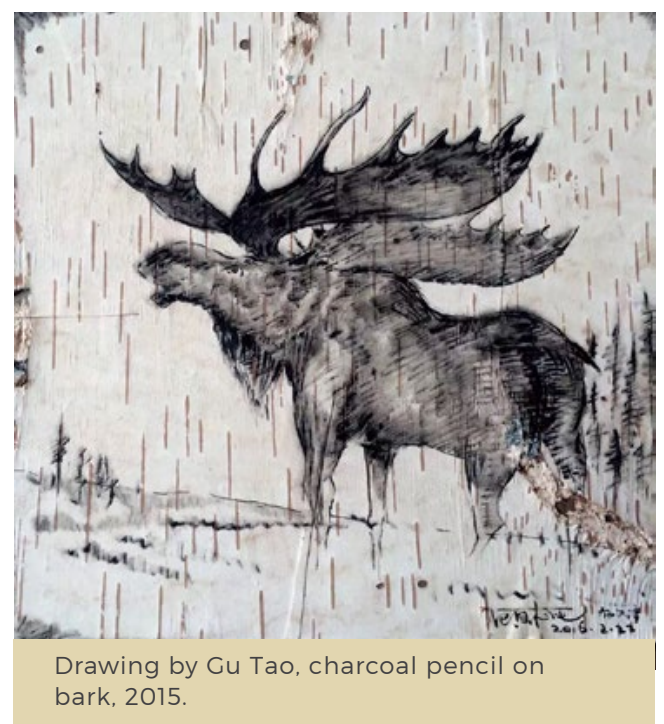


The disappearance of the moose means extinction for the Evenki. Uprooted from the forest, the Evenki culture is preserved only in the form of cultural representations and museum artefacts. In the movie, we see Weijia watching propaganda performances and television documentaries celebrating the vitality and economic development of the Evenki culture under Communist Party leadership.

\section{Blood Relatives}

We can learn about the Evenki's contemporary predicament by looking across the ocean at the history of genocide and sedenterisation of Native American nations in the United States. Despite a prevalent impulse among China watchers to blame China for all of the world's human rights violations, the destruction of indigenous culture is not particularly Chinese, Maoist, or authoritarian. The Chinese Communist Party's (CCP) tyranny of progress is only one variant of settler colonialism. In the United States, the genocide of the Native Americans was arguably more extensive, violent, and merciless than the complex and uneven histories of the CCP's policies and treatment of its minority populations, which were at least formulated under the banner of socialist equality.

The eradication of indigenous cultures also belongs to the histories of the moose in the forests of Hulunbuir and bison in the Dakota plains. In her book Dispatches from Dystopia: Histories of Places Not Yet Forgotten (2015), historian Kate Brown argues: 'The story of Custer and his defeat by Crazy Horse at the battle of Little Big Horn is well known. So, too, are his infamous trips through the plains shooting bison and leaving the stench of rotting flesh ... Custer was one of a number of Americans who felt that the extermination of the buffalo would inspire the Indians to settle down.' For pastoral nations like the Sioux, Cheyenne, and Crow, the end of the buffalo meant the end of their way of life. In the haunting words of Plenty Coup, the leader of the Crow Nation at the end of nineteenth and turn of the twentieth centuries: 'But when the buffalo went away the hearts of my people fell to the ground, and they could not lift them up again. After this nothing happened.'

In his book Radical Hope: Ethics in the Face of Cultural Devastation (2006), philosopher Jonathan Lear interprets Plenty Coup's statement to mean that life for the Crow went on after the buffalo died, but there was no longer a world in which actions could be ascribed familiar meanings. As Lear explains, the same action that meant one thing in the past (display of martial valour and courage) meant an entirely different thing on the reservation (an illegal and barbaric practice). The only bridge between these two worlds is one of memory and loss. Similarly, life for the Evenki continues in the settlements, and Weijia's life continued when he moved to Hainan to pursue a marriage based on an advertisement his mother placed in the newspaper, but it is life without a world.

The end of the world does not mean the end of state violence because new and counter-worlds will always be born from the memories of the past. As I write this essay in February 2017, the United States federal government, US Army Corps of Engineers, in tandem with oil corporations are preparing to build an oil pipeline (Dakota Access Pipeline or DAPL) through the Standing Rock Sioux Reservation's sacred burial grounds despite massive and ongoing protests and environmental concerns (NYC Stands with Standing Rock Collective 2016). At an earlier stage in the conflict in November 2016, militarised police deployed tear gas, rubber bullets, concussion grenades, and water cannons on peaceful protestors and encampments of 'water protectors' composed of over two 
hundred indigenous nations. In China, Inner Mongolian grasslands are being devastated in part due to extensive coal mining operations (Sorace 2016). Increasingly frequent protests by ethnic Mongolians over the loss of traditional grazing lands are inevitably greeted by riot police.

\section{Alcoholism}

The possibility of rebuilding a new world requires political resistance, organisation, and hope, without which there is despair. Unable to maintain their traditional livelihoods, marooned in townships with bleak economic prospects, many Evenkis became alcoholics. In an interview, Gu Tao stated that drinking was 'everywhere in the forest (Cunliffe 2015). Everybody was drinking, so much that alcohol seemed to permeate the air. I wanted to capture this aspect of their lives, and the accompanying loss of their traditional way of life. This loss caused suffering which is the reason they turned to alcohol.'

Weijia is an alcoholic because his world is over. In the film, he is clearly, and in his own words, 'drinking himself to death'. Aware that he is destroying himself, he embraces the decision as the only one available to him in lieu of a world and out of fidelity to the past. 'The guns were gone after we moved, we had nothing to do, so we started drinking. Drinking heavily. People started dying. Already eight of us have died. Eight of us have fucking died from drink. We're lost. Our culture, our guns are gone. So we drink.'

Drinking in this context is not a response to boredom. Weijia is indeed busy throughout the film. He tends to reindeer, gets married, writes poetry, half-heartedly attends an English lesson. Although being busy keeps him alive, it does not relieve him from the knowledge, which is a permanent ache and void, that his world no longer exists. It is also clear from the film that drinking does not numb the pain but in fact heightens it. Weijia confesses that if he does not drink, he is unable to speak-which is to say, drinking immerses him in reverie about the past, where speech is meaningful.

Weijia is not drinking to forget; he is drinking to remember. His drunkenness prevents him from being reconciled to the world being thrust upon him. He is frequently kicked out of the settlement for drinking; he is unable to sustain his marriage; because of drinking, his new projects are doomed to failure. In this light,

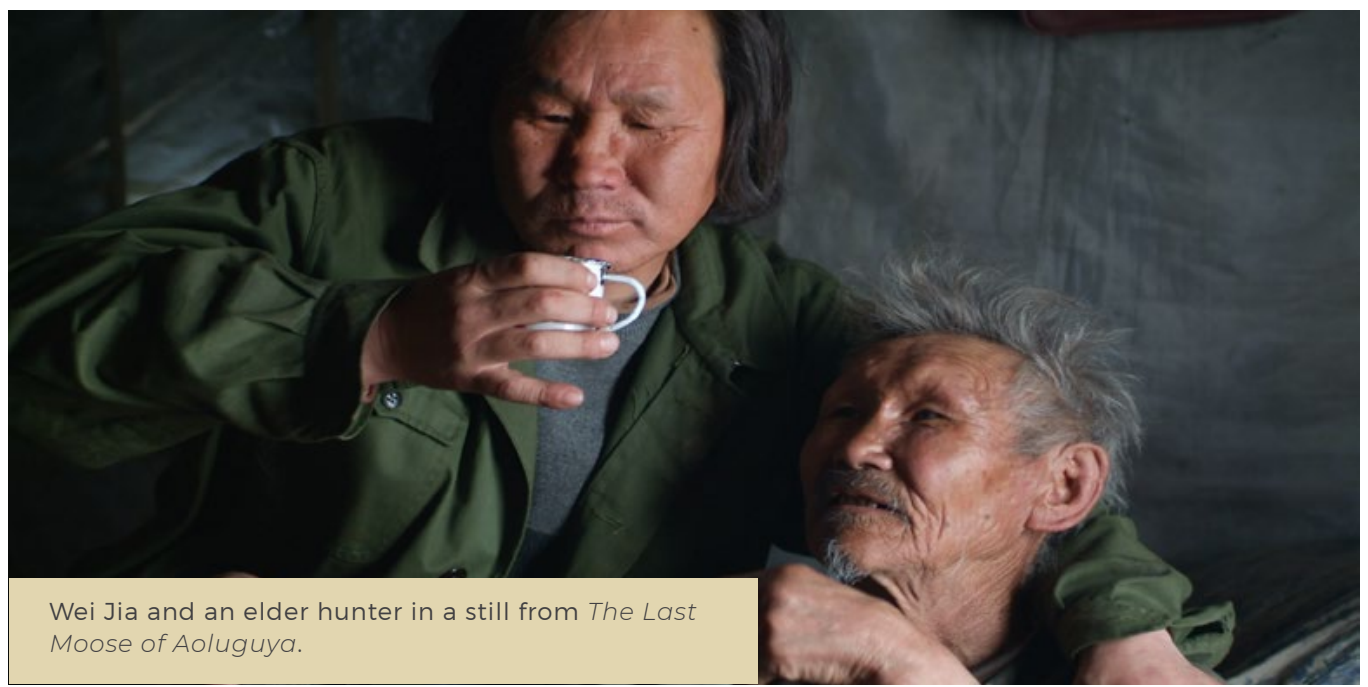


alcoholism becomes a self-conscious mode of sabotage and refusal of a world in which he is a stranger. 'To be fucking honest, it's like those Japanese samurai [author's note: he makes a cutting sound to mimic the practice of seppuku] ... Let me just say it straight, to lose your culture, it's like losing everything and so we begin to wither away. Drink! Just drink yourself to death.' These are not incoherent ramblings but clearsighted insights into the choices available to him (perhaps it is when we believe we are sober that we can trick ourselves more effectively into accepting the unacceptable). For Weijia, to stop drinking would betray the past.

Weijia's alcoholism is neither romantic nor pathological. As he puts it, 'I'm not afraid of being poisoned, that's what drinking is. If you don't get poisoned, then what's the point?' Following Lear's argument about the Crow, I suggest that Weijia's selfdestructiveness is not psychological, but an objective assessment of his (non)place in the world: 'We live in a modern society now, it's swallowed us up. Our hunting culture is disappearing. The society is becoming industrialised, and turning the world into a miserable place. If the police of a civilised world, shot at me, then I'd say, "Go ahead, shoot!" The wish to die is not a rejection of himself but of the world on offer. It seems that Weijia is not only mourning the loss of his traditional lifestyle but is also cognizant of the violence of the world promised to replace it. What kind of world is he being asked to join?

\section{On Extinction and Being Human}

Why is the fate of nomadic, reindeer people in the remote regions of Inner Mongolia so haunting? When we watch Weijia's self-destruction on the screen, we see people that we know, including our own future possibilities. Gu Tao rejects the label of being an 'anthropological filmmaker', I suspect in part because Weijia's situation of living amidst cultural collapse belongs to the human condition. Undoubtedly, the world is full of cultural plurality, textures and contexts, meanings and misunderstandings, norms and transgressions, all of which require detailed attention to, and knowledge of, the local. But details are not discrete fortresses impervious to collapse-they are fragile dwellings built on the edge of a void.

No one expects that their world will disappear. The possibility that the world can collapse is probably the kind of knowledge that Nietzsche suggested we must forget to remain alive. The cultural extinction of the Evenki is an extreme example, but collapses of different scales and intensities are happening all the time. When a factory shutters in a remote town due to capital flight and takes people's prospects at a better life along with it, is this not also a form of world collapse? When residents must permanently evacuate their villages in Alaska because of climate change, do their worlds remain intact apart from the place that held them together? When Weijia is living in China's southern island of Hainan, he remarks, 'I'm not interested in the sites here. The big hotels... that has nothing to do with me. I'm just interested in local villages' and their customs and ways of life. Perhaps his motivation to research other villages was driven by a sensibility of camaraderie through the shared experience of loss and precarity. Perhaps he wanted to find other possibilities for coping with extinction. 
This text is taken from Gilded Age: A Year of Chinese Labour, Civil Society, and Rights, Made in China Yearbook 2017, edited by Ivan Franceschini and Nicholas Loubere, published 2018 by ANU Press, The Australian National University, Canberra, Australia.

doi.org/10.22459/MIC.04.2018.38 